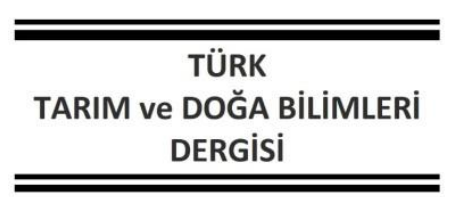

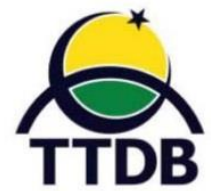

www.dergipark.gov.tr/turkjans

Araştırma Makalesi

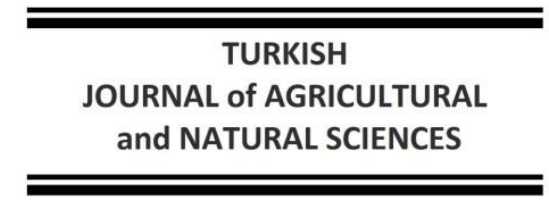

and NATURAL SCIENCES

\title{
Posof Yöresi Elmalarında Periyodisiteye Kısmen Eğilim Gösteren Tipler\&
}

\author{
Abdullah OSMANOĞLU1* ${ }^{1 *}$ Fikri BALTA
}

\begin{abstract}
${ }^{1}$ Bingöl Üniversitesi, Ziraat Fakültesi, Bahçe Bitkileri Bölümü, Bingöl.
${ }^{2}$ Ordu Üniversitesi, Ziraat Fakültesi, Bahçe Bitkileri Bölümü, Ordu.

*Sorumlu Yazar: aosmanoglu@bingol.edu.tr
\end{abstract}

Geliş Tarihi: 04.05.2021 Düzeltme Geliş Tarihi: 07.06.2021 Kabul Tarihi: 30.06.2021

\section{$\overline{O ̈ z}$}

Bu araştırma, Posof ilçesi ve köylerinde, mevcut genetik varlığı içerisinde, elma ağaçlarının periyodisiteye eğilim durumlarını araştırmak üzere yapılmıştır. Yörenin elma çeşit varlığı içerisinde değerlendirilmeye alınan elmalar arasından 18 genotip periyodisiteye eğilimi bakımından 'kısmen periyodisite gösteren tipler' olarak isimlendirilmiştir. Araştırmanın sonuçlarına göre; değerlendirilmeye değer görülen 111 elma genotipinden 18'inde (POSOF-01, POSOF-15, POSOF-16, POSOF-22, POSOF-23, POSOF-36, POSOF-46, POSOF-55, POSOF-59, POSOF-64, POSOF-65, POSOF-74, POSOF-81, POSOF-90, POSOF-91, POSOF-95, POSOF-104 ve POSOF-109) düzenli meyve alınımı 'kısmen' olmuştur. Bu tiplerinde; ortalama olarak, meyve eti sertliği 9.02-23.7 lb, meyve ağırlığı 114.8-252.8 gr, meyve eni 66.1-92.3 mm, suda çözünebilir kuru madde miktarı ise \%9.8-13.4 olarak belirlenmiştir. Tiplerde, hasada en erken Ekim ayının birinci ve en geç ikinci haftasında başlanırken, tam çiçeklenmeden hasada kadar geçen gün sayıları 140-166 gün arasında değişiklik göstermiştir.

Anahtar kelimeler: Elma, Kısmi Periyodisite, Seleksiyon, Posof

\section{Part-Periodic Genotypes in Apple Population of Posof District}

\begin{abstract}
This research was carried out in order to investigate the tendency of apple trees to periodicity within the existing genetic materials in Posof district and villages. Eighteen genotypes among the apples that were evaluated within this existing genetic materials of the region were named as "types with partial periodicity" in terms of their tendency to periodicity. According to the results of the research; in 18 out of 111 apple genotypes deemed worthy of evaluation (POSOF-01, POSOF-15, POSOF-16, POSOF-22, POSOF-23, POSOF-36, POSOF-46, POSOF-55, POSOF-59, POSOF-64, POSOF-65, POSOF-74, POSOF-81, POSOF-90, POSOF-91, POSOF-95, POSOF-104 and POSOF-109) fruit bearing was 'partial fruit bearing'. In these types on average, fruit firmness was determined as $9.02-23.7 \mathrm{lb}$, fruit weight as $114.8-252.8 \mathrm{~g}$, fruit width as $66.1-92.3 \mathrm{~mm}$, solid soluble content as $9.8-13.4 \%$. In types, harvesting started in the first week of October at the earliest and the second week of October at the latest, while the number of days from full bloom to harvest varied between 140-166 days.
\end{abstract}

Key words: Apple, Part-periodicity, Selection, Posof

\section{Giriş}

Anadolu elmanın anavatanları içerisinde yer almakla birlikte özellikle; İç Anadolu'da nemli vadilerde, Doğu Anadolu'nun alçak vadilerinde, Ege bölgesinde 500 m den daha yüksek kısımlarında,
Güneydoğu Anadolu'da ise 1000-1200 m yüksekliklerinde yetişmektedir (Özbek, 1978). Ayrıca Türkiye'nin ekolojik özellikleri bakımından büyük farklılıklar göstermesi her bir farklı ekolojiye uygun standart ve mahalli olarak yetiştirilen çeşitlerin de fazlaca olmasına imkan tanımıştır (Güleryüz, 1977; Özbek, 1977). Tür, çeşit ve tip 
bazındaki bu zenginlik meyvelerin binlerce yıllık yetiştirilme periyotlarında meydana gelen tabii melezlemeler ve tabii seleksiyonlardan kaynaklanmaktadır. Posof'un sahip olduğu ekolojik yapısı sebebiyle, ülkemizin diğer yörelerinde olduğu gibi çok sayıda farklı elma tiplerine ev sahipliği yapmaktadır (Osmanoğlu, 2008).

Periyodisiteye eğilimi bulunan meyve türlerinin başında gelen meyvelerden biri de elmadır. Periyodisite ile ağaçta; var yılında oluşan ağır meyve yükünden yeteri sürgün oluşturamadığı, çok yılında az veya verimsiz olan fazlaca verimsiz vejetatif büyüme sebebiyle fizyolojik bozulmalar göstermektedir (Atay ve ark., 2016). Türlere ve hatta tür içindeki çeşitlere göre de farklılık gösteren ve meyve yetiştiriciliğinde istenmeyen bu fizyolojik olayda hem üretici, hem de tüketici açısından büyük bir sorun olarak ortaya çıkmaktadır.

Bu sorunun kaynağı ağacın çok yılında çok fazla miktarda meyve yükü olduğundan bütün güç bu meyveleri büyütmeye harcanmasından kaynaklanmaktadır (Osmanoğlu, 2019). Böylece ağaç, önündeki kışı atlatacak yeteri besini sağlayabilmek için geç dinlenmeye girmektedir. Bu durum sonbaharda gelen erken donlara ve kışın olabilecek sert soğuklardan ve don olayından zarar görmesi kaçınılmaz olmaktadır. Ayrıca, meyvelerin tatsız, renksiz ve kokusuz olmasına sebep olmanın ötesinde üreticinin düzenli bir ürüne/gelire kavuşmasına engel bir durum olarak karşımıza çıkmaktadır. Tüketici açısından ise bu sorun; var yılında uygun fiyatla ulaştığı meyveye yok yılında daha yüksek fiyatla elde etmesi demektir (Osmanoglu, 2021).

Islahçıların başlıca amaçlarından olan, meyve kalitesi, erkencilik, hastalıklara mukavemet, farklı iklim şartlarına adaptasyon, depolanamaya uygunluk gibi konuların yanında düzenli ve yüksek verim, meyve kalitesinin en önemli özellikleri arasındadır (Janick ve ark. 1996). Çeşit zenginliği meyve ıslahçılarına, türlü amaçlara yönelik yetiştirilecek yeni çeşitlerin elde edilmesinde şüphesiz değerli bir kaynak teşkil edeceğini unutmamak gerekir (Özbek, 1993).

Bu bakımdan, Posof ilçe merkezi ve bağlı köylerinin, elma ıslahı açısından araştırmaya değer görülmesi, elma genetik kaynaklarımız bakımından geniş elma varlığına sahip olmasından ileri gelmektedir. Bu çalışma ile yörenin sahip olduğu mahalli elma çeşitlerinin morfolojik, pomolojik ve fenolojik özelliklerinin belirlemesi yanında, periyodisiteye eğilimleri ile bazı botanik özelliklerinin ortaya konulması amaçlanmıştır.

\section{Materyal ve Metot}

Çalışanın materyali, Posof ilçe merkezinde ve köylerinde yetişen yerel elma ağaçlarıdır. Bu çöğür ağaçlardan ürünün hem pazar değeri, hem de elma çeşit ıslahında önemli kriterler arasında sayılan meyve eni, meyve ağırlığı, meyve eti sertliği ve meyve rengi gibi hususlar göz önünde bulundurularak meyve örnekleri alınmıştır. Mevcut varlığı temsil etmesi bakımından alınan bu 111 ürün üzerinde morfolojik, pomolojik, fenolojik ve periyodisite gibi durumları incelenmiştir.

Incelenen bu ürünlerde morfolojik, pomolojik ve fenolojik incelemeler yapılarak veriler birlikte irdelenmiştir.

Morfolojik özellikler olarak; ağacın yaşı, taç yüksekliği, taç genişliği, ağacın habitüsü, gelişme kuvveti, gövde çevresi ve ana dal sayıları kaydedilmiştir.

Pomolojik özellikleri bakımından ortalama olarak; meyve eni, meyve boyu, meyve ağırlığı, meyve eti sertliği, meyve kabuk kalınlığı, meyve hacmi, meyve yoğunluğu, şekil indeksi ile tohum eni, boyu ve kalınlığı gibi ölçümler yapılmıştır. Bunun yanında tesadüfî olarak alınmış 10 ürün üzerinde kumpas yardımıyla (0.05 mm'ye duyarlı); meyve sapı uzunluğu ve kalınlığı $(\mathrm{cm})$, sap çukuru eni ve derinliği $(\mathrm{cm})$, çiçek çukuru eni ve derinliği $(\mathrm{cm})$, çekirdek evi boyu ve eni $(\mathrm{cm})$, tohum boyu, tohum eni ve tohum kalınlığı $(\mathrm{cm})$ üzerinde ölçümler yapılmıştır.

Ürünlerden ayrı ayrı elde edilen sularında $\mathrm{pH}$, suda çözünebilir kuru madde miktarı (SÇKM) ve titre edilebilir asit miktarına da bakılmıştır.

Tip numarası verilerek işaretlenmiş olan ağaçların fenolojik özellikleri olarak; tomurcuk patlaması, çiçeklenme başlangıcı, tam çiçeklenme ile birlikte tam çiçeklenme sonu ve hasat başlangıcı tarihleri gözlemlenerek not edilmiştir. Bu notlar üzerinden de her tipin ayrı ayrı tam çiçeklenmeden hasada kadar geçen süreleri gün sayıları hesaplanıp kaydedilmiştir.

Periyodisiteye eğilim durumları bakımından ise; iki yıllık gözlem sonuçları ve üreticinin beyanı dikkate alınarak ortaya konulmaya çalışılmış, her yıl yeteri miktarda ürün veren tiplere 'YOK', var yılı ile yok yılı arası bir durum gösteren tiplere 'KISMEN' bir yıl ürün verip sonraki yıl ürün veremeyen tiplere 'VAR', diye tanımlanmıştır.

\section{Bulgular ve Tartışma}

İncelenen tipler üzerinde iki yılı aşan gözlemlere göre periyodisiteye karşı eğilimleri araştırılmıştır. Popülasyon içerisinde kısmen düzenli meyve veren olduğu gibi düzenli yada düzensiz ürün veren tiplerde görülmüştür. Incelemeye değer görülen 111 genotip içerinden 
onsekiz (18) tanesinde düzenli ürün vermeye yatkınlık olduğu görülmüştür (Çizelge 1 ; Şekil 1). Luby ve Bedford, (2006)'un bildirdiğine göre 'Ariane' çeşidinin her yıl düzenli ürün vermesi için seyreltmeye ihtiyaç duyduğunu, 'Crimson Crisp' çeşidinin ise çok meyve tutması halinde iki yılda bir ürün verdiğini ifade etmiştir. Janick, (2001), 'GoldRush' elma çeşidinin periyodisiteye eğilim gösterdiği ancak seyreltme yapılarak bu sorunun ortadan kaldırılabileceği bildirmiştir. Elma çeşit ve genotiplerinde yürütülen çalışmalarda araştırıcılar incelediği tiplerin büyük kısmının periyodisite gösterdiği belirtilirken (Pırlak ve ark., 1997; Balta ve ark., 2015), bazı araştırmacılar ise inceledikleri tiplerden 19'unda kısmen periyodisiteye eğilim görüldüğünü tespit etmişlerdir (Kaya ve Balta, 2014)

Çizelge 1. Seçilen tiplerde periyodisite durumları

\begin{tabular}{ccccc}
\hline Tip No & $\begin{array}{r}\text { ilk yıl (verim) } \\
\text { var/0:yok }\end{array}$ & $\begin{array}{c}\text { íkinci yıl (verim) } \\
\text { 1: var/0:yok }\end{array}$ & Nümerik Değer* & Periyodisite \\
\hline POSOF-01 & 1 & 1 & 2 & KISMEN \\
POSOF-15 & 1 & 1 & 2 & KISMEN \\
POSOF-16 & 1 & 1 & 2 & KISMEN \\
POSOF-22 & 1 & 1 & 2 & KISMEN \\
POSOF-23 & 1 & 1 & 2 & KISMEN \\
POSOF-36 & 1 & 1 & 2 & KISMEN \\
POSOF-46 & 1 & 1 & 2 & KISMEN \\
POSOF-55 & 1 & 1 & 2 & KISMEN \\
POSOF-59 & 1 & 1 & 2 & KISMEN \\
POSOF-64 & 1 & 1 & 2 & KISMEN \\
POSOF-65 & 1 & 1 & 2 & KISMEN \\
POSOF-74 & 1 & 1 & 2 & KISMEN \\
POSOF-81 & 1 & 1 & 2 & KISMEN \\
POSOF-90 & 1 & 1 & 2 & KISMEN \\
POSOF-91 & 1 & 1 & 2 & KISMEN \\
POSOF-95 & 1 & 1 & 2 & KISMEN \\
POSOF-104 & 1 & 1 & 2 & KISMEN \\
POSOF-109 & 1 & 1 & 2 & KISMEN \\
\hline
\end{tabular}

Araştırılan elmalar içerisinde geç hasat edilen meyve (Posof-104 ve Posof-109) numaralı tiplerdir. Bu iki tip haricinde olanlar ekim ayının birinci ve ikinci haftasında hasat olumuna geldikleri belirlenmiştir. İkinci haftada hasat edilenler olarak (Posof-16, 22, 64, 65, 81, 90, 91, 95) tespit edilmiştir. Bu 18 tipte tam çiçeklenmeden hasadın başlangıcına kadar geçen süre, 140 gün (Posof-91) ile 166 (Posof-16) gün olarak hesaplanmıştır (Çizelge 2). Birçok araştırıcı tarafından yürütülen benzer çalışmalarda, Balta ve ark., (2015), Kumru yöresinde 74-163 gün, Oğuz ve Aşkın, (1993), Erciş yöresi yerel elmalarında 88-153 gün, (Akça ve Şen, 1990), Gürün yöresi yazlık çeşitlerinde 113-142 gün, güzlük çeşitlerinde 150-154 gün ve kışlık çeşitlerinde ise 153-156 gün olduğu bildirmişlerdir. Konya yöresi yazlık elma tiplerinde tam çiçeklenmeden hasada kadar geçen süre 85-140 gün (Bolat, 1991), Yukarı Çoruh vadisi elmalarında 113-157 gün (Karlıdağ ve Eşitken, 2006), Tokat merkez ilçe mahalli elma genotiplerinde 106-159 gün (Edizer ve Bekar, 2006) arasında olduğunu belirtmişlerdir. Granger ve ark. (1997), 'Pirimever' isimli elmanın Frelighsburg'da 7-10 Ekim arası olgunlaştığını ifade ederken, Hernandez ve ark., (2003), 'Blankuina', 'Cristalina', 'Marialena', 'Reineta Encarnada', 'Raxao' ve 'Teorica' çeşitlerinde tam çiçeklenmesi 28 Nisan 20 Mayıs, hasat tarihi olarak 22 Eylül ile 23 Ekim tarihleri arasında olduğunu, çeşitlerde tam çiçeklenmeden hasada kadar geçen süre 134 (Marialena) ile 179 (Reinata Encarnada) gün arasında gerçekleştiğini kaydetmiştir. 
Çizelge 2. Kısmen periyodisite gözlenen tiplerde hasat zamanı ve gün sayıları

\begin{tabular}{cccc}
\hline Tip No & Tam Çiçeklenme & Hasat BaşlangıCı & TÇHG* \\
\hline POSOF-01 & 11 Mayıs & Ekim I. Haftası & 152 \\
POSOF-15 & 17 Mayıs & Ekim I. Haftası & 158 \\
POSOF-16 & 20 Mayıs & Ekim II. Haftası & 166 \\
POSOF-22 & 1 Haziran & Ekim II. Haftası & 156 \\
POSOF-23 & 14 Mayıs & Ekim I. Haftası & 155 \\
POSOF-36 & 14 Mayıs & Ekim I. Haftası & 156 \\
POSOF-46 & 15 Mayıs & Ekim I. Haftası & 157 \\
POSOF-55 & 16 Mayıs & Ekim I. Haftası & 158 \\
POSOF-59 & 17 Mayıs & Ekim I. Haftası & 163 \\
POSOF-64 & 17 Mayıs & Ekim II. Haftası & 163 \\
POSOF-65 & 17 Mayıs & Ekim II. Haftası & 157 \\
POSOF-74 & 18 Mayıs & Ekim I. Haftası & 164 \\
POSOF-81 & 18 Mayıs & Ekim II. Haftası & 142 \\
POSOF-90 & 23 Mayıs & Ekim II. Haftası & 140 \\
POSOF-91 & 25 Mayıs & Ekim II. Haftası & 149 \\
POSOF-95 & 16 Mayıs & Ekim II. Haftası & 144 \\
POSOF-104 & 30 Mayıs & Ekim III. Haftası & 143 \\
POSOF-109 & 31 Mayıs & Ekim III. Haftası & 15 \\
\hline
\end{tabular}

* TÇHGS: Tam Çiçeklenmeden Hasada Kadar Geçen Gün Sayısı

Kısmen periyodisite gözlemlenen bu 18 elma tipinde; meyve ağırlığı 114.8 g (Posof-90) ile 252.8 g (Posof-22), meyve boyu $54.1 \mathrm{~mm}$ (Posof-109) ile $71.7 \mathrm{~mm}$ (Posof-65), meyve eni $66.1 \mathrm{~mm}$ (Posof90) ile $92.3 \mathrm{~mm}$ (Posof-81), meyve eti sertliği 9.6 libre (Posof-16) ile 23.7 libre (Posof-90), $\mathrm{pH}$ değeri 3.77 (Posof-22) ile 5.22 (Posof-59), suda çözünebilir kuru madde miktarı \%9.8 (Posof-91 ve 104 ) ile \%13.4 (Posof-64), titre edilebilir asit oranı (TEA) \%0.23 (Posof-59) ile \%1.21 (Posof-90) değerleri tespit edilmiştir (Çizelge 3, Çizelge 4, Çizelge 5). Tolmacheva, (1991), 'Foredzhan çeşidinde $164 \mathrm{~g}$, 'Krasynoyarsk' çeşidinin 30-40 g, Goffreda ve ark., (1995), 'NJ55' çeşidinde 220 g, Lei ve ark. (1996), '135-1' çeşidinde $135 \mathrm{~g}$ ve Fischer ve Fischer, (2002), 'Pinova' çeşidinde 130-150 g olduğu ifade etmiştir. Kırkaya ve ark., (2014), 76.2-247.2 g arasında değiştiğini belirlemiştir. Ülkemizin farklı yörelerinde elma genetik kaynakları üzerine yapılan ilgili çalışmalarda meyve eni değerleri; Van yöresinde tespit edilen elma tiplerinde $42.6 \mathrm{~mm}$ ile $59.63 \mathrm{~mm}$ (Bostan ve ark. 1997), Ulus ve Maden ilçelerinde 35.1-73.5 mm (Karadeniz ve Gökalp,
1996), Camili'de (Artvin) yetişen yerel elmalarda $50.6 \mathrm{~mm}$ - $83.7 \mathrm{~mm}$ (Serdar ve ark. 2007), Iğdır yöresi mahalli elmalarında $68.9 \mathrm{~mm}$ ile $83.0 \mathrm{~mm}$ (Balta ve Uca, 1996), Ahlat yöresi mahalli elmalarında $43.50 \mathrm{~mm}$ ile $79.10 \mathrm{~mm}$ (Şen ve ark. 1992), Konya yöresi yazlık elma tiplerinde 56.71 $\mathrm{mm}$ ile $80.18 \mathrm{~mm}$ (Bolat, 1991), Tokat yöresi mahalli elmalarında $56.6 \mathrm{~mm}$ ile $86.3 \mathrm{~mm}$ (Edizer ve Güneş, 1997). Gümüşhane yöresi yerel elmalarında $57.27 \mathrm{~mm}$ ile $80.77 \mathrm{~mm}$ (Şenyurt ve ark., 2016), olduğunu ifade etmiştir. Meyve özelliklerinin belirlenmesinde önemli karakterlerden biri de meyve eti sertliğinin belirlenmesidir. Bu konuda yürütülen çalışmalardan, Konya yöresi yazlık elma tiplerinde meyve eti sertliği 8.21 lb- 18.27 lb (Bolat, 1991), Erciş yöresi yerel elmalarında $6.16 \mathrm{lb}-17.3 \mathrm{lb}$ (Oğuz ve Aşkın, 1993), Tokat merkez ilçe mahalli elma genotiplerinde $15.8 \mathrm{lb}$-28.1 lb (Edizer ve Bekar, 2006), Yukarı Çoruh vadisindeki elmalarda $8.14 \mathrm{lb}$ 11.55 lb (Karlıdağ ve Eşitken, 2006), "Yomra" ve "Demir" elmasında 6.8- $8.75 \mathrm{lb}$ arasında olduğunu bildirilmiştir (Bostan ve Yılmaz, 2015). 
Çizelge 3. Kısmen periyodisite gözlenen tiplerin bazı meyve değerleri

\begin{tabular}{|c|c|c|c|c|c|c|c|}
\hline TiP NO & $\begin{array}{c}\mathrm{MB} \\
(\mathrm{mm}) \\
\end{array}$ & $\begin{array}{c}\mathrm{ME} \\
(\mathrm{mm})\end{array}$ & $\begin{array}{c}\text { MA } \\
(\mathrm{g}) \\
\end{array}$ & $\begin{array}{c}\text { MES } \\
\text { (lb) } \\
\end{array}$ & $\begin{array}{c}\mathrm{KK} \\
(\mathrm{mm}) \\
\end{array}$ & $\begin{array}{c}\mathrm{SU} \\
(\mathrm{mm}) \\
\end{array}$ & $\begin{array}{c}\text { SK } \\
(\mathrm{mm}) \\
\end{array}$ \\
\hline POSOF-01 & $63.0 \pm 1,5$ & $67.4 \pm 1,2$ & $127.7 \pm 11.1$ & $12.9 \pm 0.7$ & $0.25 \pm 0.01$ & $26.2 \pm 0.9$ & $1.6 \pm 0.02$ \\
\hline POSOF-15 & $68.1 \pm 0.7$ & $76.9 \pm 1.3$ & $191.8 \pm 4.2$ & $20.8 \pm 0.8$ & $0.29 \pm 0.01$ & $14.9 \pm 0.5$ & $2.8 \pm 0.03$ \\
\hline POSOF-16 & $67.3 \pm 1.3$ & $84.8 \pm 1.5$ & $210.5 \pm 8.0$ & $9.6 \pm 0.2$ & $0.27 \pm 0.01$ & $15.4 \pm 0.1$ & $2.2 \pm 0.14$ \\
\hline POSOF-22 & $69.4 \pm 1.1$ & $91.0 \pm 1.5$ & $252.8 \pm 8.7$ & $12.1 \pm 0.4$ & $0.23 \pm 0.01$ & $13.0 \pm 1.0$ & $2.4 \pm 0.10$ \\
\hline POSOF-23 & $71.3 \pm 1.0$ & $82.7 \pm 1.3$ & $239.0 \pm 8.3$ & $11.7 \pm 0.3$ & $0.22 \pm 0.01$ & $22.9 \pm 2.3$ & $2.0 \pm 0.15$ \\
\hline POSOF-36 & $65.3 \pm 1.2$ & $77.1 \pm 1.4$ & $183.6 \pm 8.0$ & $11.9 \pm 0.5$ & $0.23 \pm 0.01$ & $15.3 \pm 1.5$ & $2.8 \pm 0.25$ \\
\hline POSOF-46 & $63.3 \pm 1.4$ & $80.2 \pm 0.9$ & $164.8 \pm 9.5$ & $13.7 \pm 0.9$ & $0.27 \pm 0.01$ & $18.2 \pm 0.8$ & $1.8 \pm 0.08$ \\
\hline POSOF-55 & $57.2 \pm 1.2$ & $74.2 \pm 1.3$ & $154.3 \pm 7.7$ & $14.6 \pm 0.3$ & $0.32 \pm 0.01$ & $25.6 \pm 1.0$ & $1.7 \pm 0.08$ \\
\hline POSOF-59 & $61.4 \pm 1.8$ & $68.8 \pm 2.0$ & $127.1 \pm 1.8$ & $13.5 \pm 2.0$ & $0.26 \pm 0.01$ & $18.1 \pm 1.8$ & $1.8 \pm 0.90$ \\
\hline POSOF-64 & $71.2 \pm 1.6$ & $83.7 \pm 1.2$ & $237.2 \pm 5.0$ & $12.3 \pm 0.9$ & $0.28 \pm 0.01$ & $12.4 \pm 0.3$ & $2.3 \pm 0.14$ \\
\hline POSOF-65 & $71.4 \pm 1.6$ & $87.0 \pm 1.4$ & $238.5 \pm 7.1$ & $10.6 \pm 0.2$ & $0.28 \pm 0.01$ & $19.6 \pm 1.7$ & $2.1 \pm 0.14$ \\
\hline POSOF-74 & $64.9 \pm 0.8$ & $76.9 \pm 0.9$ & $179.9 \pm 3.2$ & $10.3 \pm 0.4$ & $0.23 \pm 0.01$ & $19.1 \pm 0.4$ & $1.9 \pm 0.07$ \\
\hline POSOF-81 & $70.0 \pm 1.0$ & $92.3 \pm 1.9$ & $248.2 \pm 11.7$ & $12.8 \pm 0.7$ & $0.27 \pm 0.01$ & $16.5 \pm 0.4$ & $3.0 \pm 0.10$ \\
\hline POSOF-90 & $56.0 \pm 2.0$ & $66.1 \pm 1.9$ & $114.8 \pm 1.9$ & $23.7 \pm 0.7$ & $0.30 \pm 0.01$ & $15.7 \pm 1.3$ & $1.9 \pm 0.45$ \\
\hline POSOF-91 & $71.2 \pm 1.5$ & $89.8 \pm 1.2$ & $246.5 \pm 7.0$ & $11.6 \pm 0.4$ & $0.30 \pm 0.01$ & $19.6 \pm 0.8$ & $2.6 \pm 0.08$ \\
\hline POSOF-95 & $66.3 \pm 1.0$ & $81.5 \pm 0.8$ & $217.2 \pm 4.8$ & $11.8 \pm 0.7$ & $0.28 \pm 0.01$ & $16.6 \pm 0.8$ & $2.3 \pm 0.16$ \\
\hline POSOF-104 & $65.2 \pm 1.0$ & $84.8 \pm 1.9$ & $208.5 \pm 8.6$ & $12.3 \pm 0.6$ & $0.28 \pm 0.01$ & $15.9 \pm 1.0$ & $2.4 \pm 0.07$ \\
\hline POSOF-109 & $54.1 \pm 1.1$ & $68.6 \pm 1.4$ & $133.3 \pm 1.5$ & $17.9 \pm 1.0$ & $0.28 \pm 0.01$ & $17.7 \pm 1.7$ & $1.8 \pm 0.29$ \\
\hline
\end{tabular}

MB: Meyve boyu, ME: Meyve eni, MA: Meyve ağırlığı, MES: Meyve eti sertliği, KK: Kabuk kalınlığı, SU: Sap uzunluğu, SK: Sap kalınlığı.

Çizelge 4. Kısmen periyodisite gözlenen tiplerin bazı meyve değerleri

\begin{tabular}{cccccccc}
\hline TIP NO & SÇE $(\mathrm{mm})$ & SÇD $(\mathrm{mm})$ & $\begin{array}{c}\text { ÇÇE } \\
(\mathrm{mm})\end{array}$ & ÇÇD $(\mathrm{mm})$ & ÇEB $(\mathrm{mm})$ & ÇEE $(\mathrm{mm})$ & $\begin{array}{c}\text { ÇB } \\
(\mathrm{mm})\end{array}$ \\
\hline POSOF-01 & $17.6 \pm 0.7$ & $10.8 \pm 0.3$ & $\mathbf{9 . 9} \pm 0.2$ & $\mathbf{5 . 6} \pm 0.11$ & $25.8 \pm 0.1$ & $28.5 \pm 0.2$ & $9.8 \pm 0.06$ \\
POSOF-15 & $19.5 \pm 1.0$ & $11.8 \pm 0.8$ & $11.4 \pm 0.9$ & $8.1 \pm 0.7$ & $26.3 \pm 1.0$ & $31.6 \pm 2.1$ & $\mathbf{6 . 7 \pm 0 . 2 2}$ \\
POSOF-16 & $21.0 \pm 1.2$ & $14.2 \pm 0.6$ & $14.5 \pm 0.5$ & $11.7 \pm 0.6$ & $25.8 \pm 1.3$ & $36.9 \pm 1.3$ & $8.4 \pm 0.04$ \\
POSOF-22 & $22.1 \pm 0.9$ & $15.1 \pm 0.9$ & $13.5 \pm 1.5$ & $12.2 \pm 1.5$ & $28.5 \pm 2.4$ & $\mathbf{3 9 . 4 \pm 1 . 5}$ & $\mathbf{1 0 . 1} \pm 0.22$ \\
POSOF-23 & $\mathbf{2 6 . 5} \pm 0.8$ & $14.7 \pm 1.0$ & $18.9 \pm 0.4$ & $10.2 \pm 0.7$ & $27.7 \pm 1.0$ & $37.2 \pm 1.0$ & $8.2 \pm 0.25$ \\
POSOF-36 & $23.4 \pm 1.4$ & $13.6 \pm 0.6$ & $14.3 \pm 1.1$ & $9.0 \pm 0.5$ & $25.7 \pm 1.0$ & $30.0 \pm 0.3$ & $8.6 \pm 0.29$ \\
POSOF-46 & $22.4 \pm 1.1$ & $13.6 \pm 0.6$ & $16.4 \pm 0.8$ & $9.1 \pm 0.7$ & $24.6 \pm 0.3$ & $33.3 \pm 0.6$ & $9.6 \pm 0.11$ \\
POSOF-55 & $21.0 \pm 0.9$ & $10.8 \pm 0.5$ & $15.0 \pm 0.7$ & $7.1 \pm 3.4$ & $23.3 \pm 0.4$ & $28.9 \pm 0.4$ & $9.3 \pm 0.11$ \\
POSOF-59 & $19.4 \pm 1.6$ & $12.6 \pm 1.1$ & $11.2 \pm 1.2$ & $8.9 \pm 1.2$ & $24.5 \pm 2.0$ & $31.6 \pm 2.3$ & $7.6 \pm 0.68$ \\
POSOF-64 & $24.2 \pm 1.4$ & $15.7 \pm 1.6$ & $\mathbf{1 9 . 3} \pm 1.8$ & $\mathbf{1 5 . 0} \pm 0.5$ & $\mathbf{3 0 . 2} \pm \mathbf{2 . 1}$ & $37.1 \pm 0.9$ & $8.8 \pm 0.20$ \\
POSOF-65 & $26.1 \pm 0.6$ & $\mathbf{1 6 . 9} \pm 0.7$ & $15.8 \pm 1.2$ & $13.5 \pm 0.6$ & $26.6 \pm 1.0$ & $39.0 \pm 1.2$ & $9.2 \pm 0.31$ \\
POSOF-74 & $21.4 \pm 1.0$ & $12.2 \pm 0.8$ & $16.0 \pm 1.0$ & $12.7 \pm 1.2$ & $24.9 \pm 0.4$ & $31.1 \pm 0.6$ & $8.1 \pm 0.08$ \\
POSOF-81 & $25.0 \pm 1.2$ & $14.7 \pm 0.7$ & $16.4 \pm 0.9$ & $11.8 \pm 0.7$ & $25.7 \pm 0.6$ & $36.3 \pm 0.6$ & $8.0 \pm 0.14$ \\
POSOF-90 & $17.9 \pm 1.0$ & $11.0 \pm 1.0$ & $12.2 \pm 0.9$ & $8.4 \pm 1.1$ & $\mathbf{1 8 . 7} \pm 1.8$ & $\mathbf{2 8 . 3} \pm 1.4$ & $7.7 \pm 0.99$ \\
POSOF-91 & $25.4 \pm 0.6$ & $14.9 \pm 0.9$ & $18.6 \pm 0.9$ & $14.5 \pm 0.8$ & $28.2 \pm 1.1$ & $35.7 \pm 1.6$ & $9.2 \pm 0.27$ \\
POSOF-95 & $21.6 \pm 0.8$ & $12.7 \pm 0.9$ & $17.2 \pm 1.0$ & $11.7 \pm 0.3$ & $28.4 \pm 0.6$ & $34.4 \pm 0.6$ & $9.0 \pm 0.16$ \\
POSOF-104 & $21.5 \pm 1.2$ & $13.2 \pm 1.6$ & $16.1 \pm 1.1$ & $13.9 \pm 0.9$ & $26.8 \pm 0.9$ & $34.4 \pm 0.6$ & $9.5 \pm 0.15$ \\
POSOF-109 & $\mathbf{1 5 . 6 \pm 1 . 8}$ & $\mathbf{1 0 . 0} \pm 0.8$ & $12.0 \pm 0.7$ & $8.1 \pm 1.1$ & $21.3 \pm 0.8$ & $28.7 \pm 0.8$ & $8.9 \pm 0.91$ \\
\hline
\end{tabular}

SÇE: Sap çukuru eni, SÇD: Sap çukuru derinliği, ÇÇE: Çiçek çukuru eni, ÇÇD: Çiçek çukuru derinliği, ÇEB: Çekirdek evi boyu, ÇEE: Çekirdek evi eni, ÇB: Çekirdek boyu. 
Çizelge 5. Kısmen periyodisite gözlenen tiplerin bazı meyve değerleri

\begin{tabular}{ccccccccc}
\hline TiP NO & ÇE $(\mathrm{mm})$ & ÇK $(\mathrm{mm})$ & Şi & $\begin{array}{c}\mathrm{MH} \\
(\mathrm{ml})\end{array}$ & $\begin{array}{c}\mathrm{MY} \\
\left(\mathrm{g} / \mathrm{cm}^{3}\right)\end{array}$ & $p \mathrm{H}$ & $\begin{array}{c}\text { SÇKM } \\
(\%)\end{array}$ & TEA (\%) \\
\hline POSOF-01 & $\mathbf{5 . 3} \pm \mathbf{0 . 0 3}$ & $2.9 \pm 0.01$ & $\mathbf{0 . 9 4}$ & 159 & 0.81 & 4.32 & 12.0 & 0.662 \\
POSOF-15 & $4.8 \pm 0.12$ & $\mathbf{3 . 3} \pm \mathbf{0 . 1 1}$ & 0.89 & 218 & 0.88 & 4.21 & 13.2 & 0.562 \\
POSOF-16 & $4.5 \pm 0.04$ & $2.4 \pm 0.04$ & 0.79 & 278 & 0.75 & 3.78 & 10.2 & 0.677 \\
POSOF-22 & $5.1 \pm 0.31$ & $2.8 \pm 0.15$ & $\mathbf{0 . 7 6}$ & 326 & 0.77 & $\mathbf{3 . 7 7}$ & 11.0 & 0.951 \\
POSOF-23 & $4.1 \pm 0.18$ & $\mathbf{2 . 1 \pm 0 . 3 5}$ & 0.86 & 307 & 0.78 & 4.24 & 10.8 & 0.523 \\
POSOF-36 & $4.6 \pm 0.15$ & $2.4 \pm 0.26$ & 0.84 & 220 & 0.83 & 4.09 & 11.2 & 1.032 \\
POSOF-46 & $4.8 \pm 0.11$ & $2.8 \pm 0.23$ & 0.86 & 195 & $\mathbf{0 . 9 7}$ & 3.88 & 11.5 & 0.523 \\
POSOF-55 & $4.6 \pm 0.37$ & $2.5 \pm 0.38$ & 0.77 & 183 & 0.84 & 4.02 & 12.0 & 0.677 \\
POSOF-59 & $4.3 \pm 0.30$ & $2.3 \pm 0.15$ & 0.82 & 160 & 0.85 & $\mathbf{5 . 2 2}$ & 11.0 & $\mathbf{0 . 2 3 0}$ \\
POSOF-64 & $5.3 \pm 0.06$ & $2.8 \pm 0.06$ & 0.85 & 293 & 0.80 & 4.41 & $\mathbf{1 3 . 4}$ & 0.697 \\
POSOF-65 & $4.3 \pm 0.29$ & $2.2 \pm 0.36$ & 0.82 & $\mathbf{3 8 8}$ & $\mathbf{0 . 6 1}$ & 4.28 & 10.6 & 0.697 \\
POSOF-74 & $4.2 \pm 0.09$ & $2.4 \pm 0.05$ & 0.84 & 214 & 0.84 & 4.28 & 10.8 & 0.811 \\
POSOF-81 & $4.4 \pm 0.05$ & $2.3 \pm 0.15$ & $\mathbf{0 . 7 6}$ & 329 & 0.76 & 4.08 & 11.4 & 0.878 \\
POSOF-90 & $4.0 \pm 0.39$ & $2.9 \pm 0.19$ & 0.85 & $\mathbf{1 3 6}$ & 0.84 & 3.96 & 12.4 & $\mathbf{1 . 2 1 0}$ \\
POSOF-91 & $\mathbf{3 . 9} \pm \mathbf{0 . 0 9}$ & $2.4 \pm 0.08$ & 0.79 & 324 & 0.76 & 4.33 & $\mathbf{9 . 8}$ & 0.523 \\
POSOF-95 & $4.5 \pm 0.05$ & $2.5 \pm 0.09$ & 0.81 & 262 & 0.82 & 4.32 & 11.4 & 0.576 \\
POSOF-104 & $4.3 \pm 0.05$ & $2.4 \pm 0.15$ & 0.77 & 295 & 0.71 & 3.79 & $\mathbf{9 . 8}$ & 0.724 \\
POSOF-109 & $4.5 \pm 0.18$ & $2.6 \pm 0.09$ & 0.78 & 140 & 0.95 & 3.95 & 12.0 & 0.640 \\
\hline
\end{tabular}

ÇE: Çekirdek eni, ÇK: Çekirdek kalınlığı, Şi: Şekil indeksi, MH: Meyve hacmi, MY: Meyve yoğunluğu, SÇKM: Suda çözünebilir kuru madde oranı, TEA: Titre edilebilir asit oranı.

Elma çeşit ve tiplerinde SÇKM içeriği, Ahlat yöresi mahalli elmalarında \%9.23 ile \%14.66 (Şen ve ark. 1992), Konya yöresi yazlık elma tiplerinde \%10.42 (E-4) ile \%16.21 (KO-3) (Bolat, 1991), İskilip ilçesi yerel 32 elma tipinde 9.3 ile 16.65 (Çorumlu,
2010), Tokat yöresi mahalli elmalarında \%10.10 ile \%12.80 (Edizer ve Güneş, 1997), Yukarı Çoruh vadisi elmalarında \%9.10 ile \%13.80 (Karlıdağ ve Eşitken, 2006), Erzincan yöresi 'Karasakı' ve 'Aksakı' elma seleksiyonlarında \%9.4 (24 Ü-1) ile \%14.9 (24

Çizelge 6. Kısmen periyodisite gözlenen tiplerin bazı ağaç değerleri

\begin{tabular}{cccc}
\hline TiP NO & $\begin{array}{c}\text { TAÇ YÜKSEKLiĞi } \\
(\mathrm{m})\end{array}$ & $\begin{array}{c}\text { TAÇ GENişLiĞi } \\
(\mathrm{m})\end{array}$ & $\begin{array}{c}\text { GÖVDE ÇEVRESi } \\
(\mathrm{cm})\end{array}$ \\
\hline POSOF-01 & 6.0 & 7.5 & 87 \\
POSOF-15 & 6.0 & 9.1 & 125 \\
POSOF-16 & 8.0 & 7.2 & 105 \\
POSOF-22 & 8.0 & 6.0 & 118 \\
POSOF-23 & 6.7 & 6.0 & 78 \\
POSOF-36 & 7.0 & 8.4 & 109 \\
POSOF-46 & 7.0 & 6.0 & 88 \\
POSOF-55 & 7.0 & 5.2 & 81 \\
POSOF-59 & 7.0 & 7.4 & 69 \\
POSOF-64 & 4.5 & $\mathbf{4 . 1}$ & $\mathbf{4 9}$ \\
POSOF-65 & 8.0 & 6.4 & 71 \\
POSOF-74 & 5.0 & 6.2 & 51 \\
POSOF-81 & 11.0 & 8.8 & $\mathbf{2 3 4}$ \\
POSOF-90 & 8.0 & 6.2 & 143 \\
POSOF-91 & 10.0 & 9.4 & 194 \\
POSOF-95 & 9.0 & 7.4 & 101 \\
POSOF-104 & 7.0 & 5.5 & 60 \\
POSOF-109 & 8.5 & 11.4 & 99 \\
\hline
\end{tabular}


M-13) (Doğan, 2001), Tokat merkez ilçe mahalli elma genotiplerinde \%9.0 ile \%16.0 (Edizer ve Bekar, 2006), 'Pink Lady' elmasının SÇKM oranının \% 12.5 ve TEA oranının \% 0.71-0.9 olarak belirlenmiştir (Cripps ve ark., (1993). Van çevresinde yapılan bir araştırmada SÇKM oranı $\% 8.50$ ile $\% 14.80$, pH değeri 3.42 ile 4.87 olarak tespit edilmiştir (Akça ve Şen, 1991).
Incelenen genotiplerin bazı botanik özelliklerine de bakılmış olup, bu ağaçların farklı gelişme kuvvetinde ve farklı habitüste olduğu görülmüştür (Çizelge . Taç yükseklikleri 4.5 m (Posof-64) ile 11.0 m (Posof-81), taç genişliği 4.1 m (Posof-64) ile 11.4 m (Posof-109) arasında değişirken, gövde çevresi $49 \mathrm{~cm}$ (Posof-64) ile $234 \mathrm{~cm}$ (Posof-81) arasında belirlenmiştir (Çizelge 6).

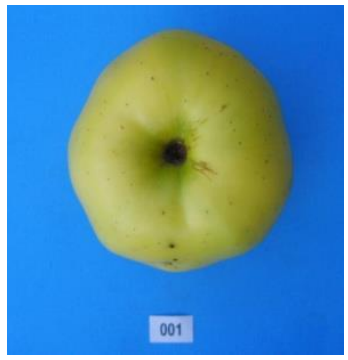

POSOF-01

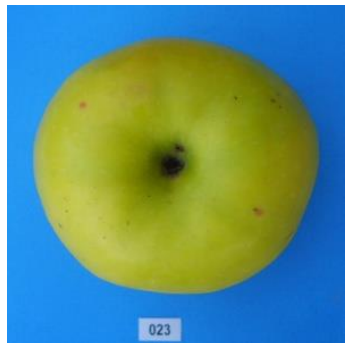

POSOF-23

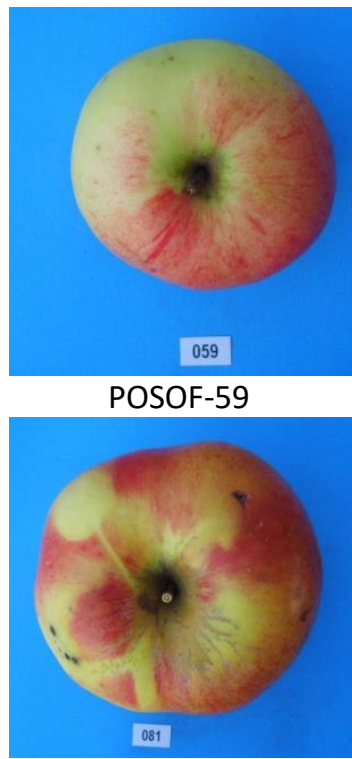

POSOF-81

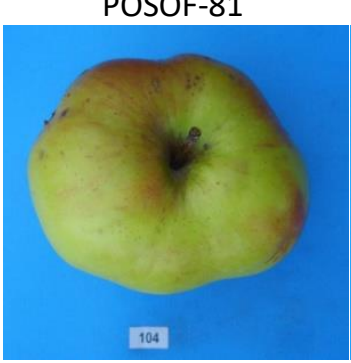

POSOF-104

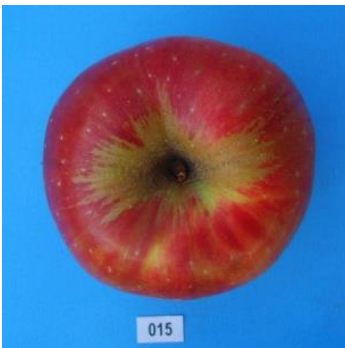

POSOF-15

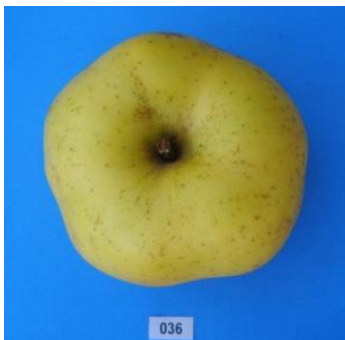

POSOF-36

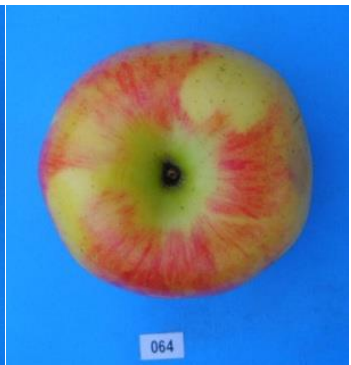

POSOF-64

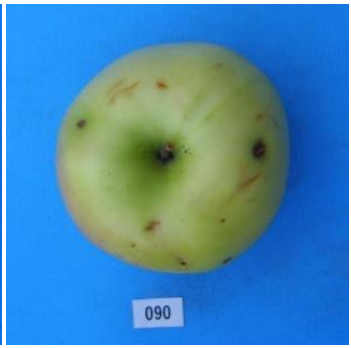

POSOF-90

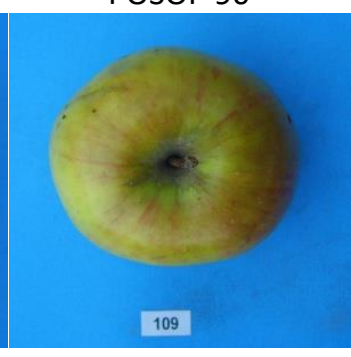

POSOF-109

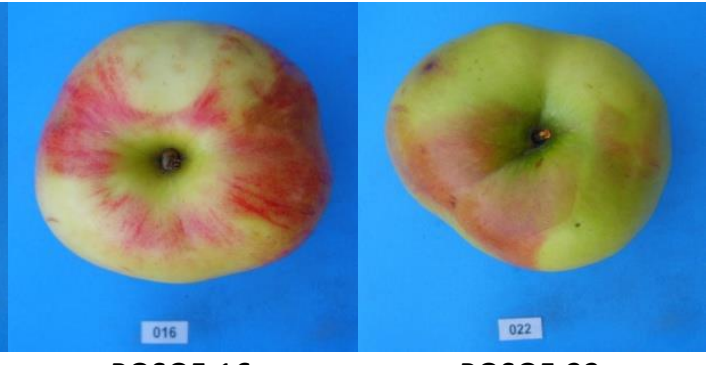

POSOF-16

POSOF-22

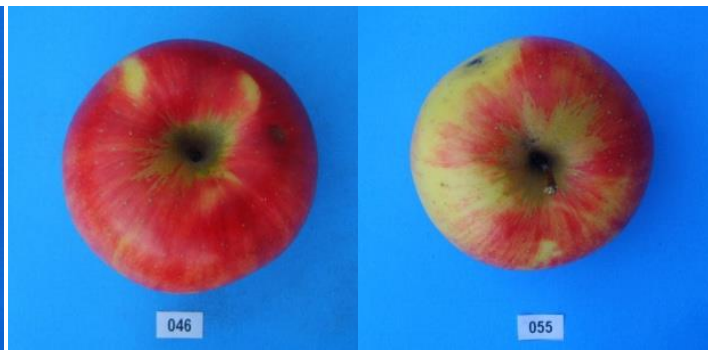

POSOF-46

POSOF-55

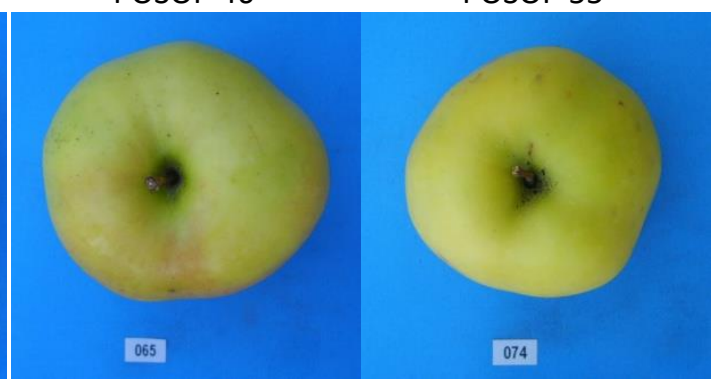

POSOF-65

POSOF-74

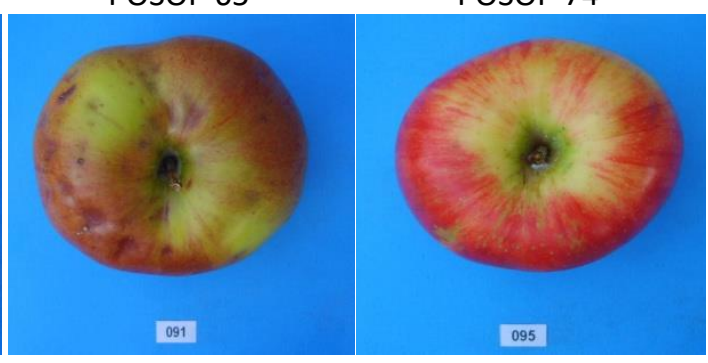

POSOF-91

POSOF-95

Şekil 1. Kısmen periyodisite gözlenen 18 elma tipine ait görünümler 


\section{Sonuç ve Öneriler}

$\mathrm{Bu}$ araştırmada, incelenen elma genotipleri arasında 18 tipte kısmen periyodisite gösteren tip olarak belirlenmiştir. Karakteristik olarak düzenli meyve alınmasının belli belirsiz oluşu, bitki genetiğinden ziyade çevre şartları ile teknik ve kültürel işlemlere de bağlı oluşu dikkate alındığında bu tiplerin üzerine biraz daha dikkatle eğilinmesi gerektiği ortaya koymaktadır. Çünkü bu tipler içerisinde standart elma tiplerine yakın ve hatta daha iyi kantite ve kalite özellikleri göster tipler bulunmaktadır. Hem yöre için, hem de ulusal meyve pörtföyümüz için kıymetli genetik kaynaklarımızdır. Elbette, bu genotiplerin gerçek değerleri ve nitelikleri standart çeşitlerle mukayeseli ve tekrarlamalı araştırmalarla detaylı olarak ortaya konulması düşüncesi daha da önem kazanmaktadır. Böylece üreticinin yaşayacağı olumsuzluklara karşı karşılaşacağı maliyet yükünden de kurtulması mümkün olacaktır.

\& Sorumlu yazara ait doktora tezinden üretilmiştir.

Çıkar Çatışması Beyanı: Makale yazarları aralarında herhangi bir çıkar çatışması olmadığını beyan ederler.

Araştırmacıların Katkı Oranı Beyan Özeti: Yazarlar makaleye eşit oranda katkı sağlamış olduklarını beyan ederler.

\section{Kaynaklar}

Akça, Y., Şen, S.M., 1990. Gürün ve Çevresinde Yetiştirilen Mahalli Elma Çeşitlerinin Pomolojik Özellikleri Üzerine Bir Araştırma. Y.Y.Ü.Z.F. Dergisi, 1 (1): 12-14.

Akça, Y., Şen, S.M., 1991. Van ve Çevresinde Yetiştirilen Mahalli Elma Çeşitlerinin Morfolojik ve Pomolojik Özellikleri Üzerine Bir Araştırma. Y.Y.Ü.Z.F. Dergisi, 1 (1): 109128.

Atay, A.N., Koyuncu, F., Atay, E., 2016. Golden Delicious Elmasında Yok Yılı Ağaçlarına ProCa Uygulamasının Vejetatif ve Generatif Gelişime Etkileri. Bahçe, Atatürk Bahçe Kültürleri Merkez Araştırma Enst. Dergisi, 45 (1): 33-38.

Balta, F., Uca, O., 1996. Iğdır'da Yetiştirilen Önemli Yazlık Mahalli Elma Çeşitlerinin Morfolojik ve Pomolojik Özellikleri. Y.Y.Ü.Z.F. Dergisi, 6 (1): 87-95.

Balta, M.F., Kaya, T., Kırkaya, H., Karakaya, O., 2015. Kumru (Ordu) Yöresinde Yetiştirilen Mahalli Elma Genotiplerinin Fenolojik,
Morfolojik ve Pomolojik Özellikleri. GOP. Üni. Zir. Fak. Dergisi, 32 (1): 47-56.

Bolat, S., 1991. Konya ilinde Kaliteli Yazlık Elma Tiplerinin Seleksiyon Yoluyla Islahı Üzerine Bir Araştırma (doktora tezi, basılmamış). AÜ. F.B. Enst., Erzurum.

Bostan, S., Z., İslam, A., Kurt, H., 1997. Mahalli Elma Çeşitlerinde Bazı Meyve Özelliklerinin Hasada Kadar Olan Değişimi ve Uygun Hasat Zamanının Belirlenmesi Üzerine Bir Araştırma. Yumuşak Çekirdekli Meyveler Sempozyumu Bildiri Kitabı, s: 259-266.

Bostan, S., Yılmaz, E., 2015. Breeding by Selection of 'Yomra' and 'Demir' Apple Varieties (Malus communis L.) Grown in Arsin and Yomra Districts (Trabzon Province, Turkey). Meyve Bilimi, 2 (1): 60-69.

Cripps, SEL., Richards, L.A., Mairata, A.M., 1993. "Pink Lady" Apple. Hort Science, 28 (10): 1057.

Çorumlu, M.S., 2010. Çorum ili iskilip ilç̧esinde Yetişen Bazı Yerel Elma Çeşitlerinin (malus communis L.) Çeşitlerinin Fenolojik ve Pomolojik Özelliklerinin Belirlenmesi (yüksek lisans tezi, basılmamış). Ordu Üni. F. B. Enst., Ordu.

Doğan, A., 2001. Erzincan ilinde Yetiştiriciliği Yapılan Sakı Elma Çeşitlerinin Klon Seleksiyonu Yolu ile Islahı (yüksek lisans tezi, basılmamış). AÜ. F.B. Enst., Erzurum.

Edizer, Y., Güneş, M., 1997. Tokat Yöresinde Yetiştirilen Yerel Elma ve Armut Çeşitlerinin Bazı Pomolojik Özellikleri Üzerine Bir Araştırma. Yumuşak Çekirdekli Meyveler Sempozyumu. 2-5 Eylül 1997, s: 53-60, Yalova.

Edizer, Y., Bekar, T., 2006. Tokat Merkez İlçede Yetiştirilen Bazı Yerel Elma Çeşitlerinin Fenlojik ve Pomolojik Özelliklerinin Belirlenmesi. GOP. Zir. Fak. Dergisi, 24 (1): 1-8.

Fischer, M., Fischer, C., 2002. Pinova Apple Cultivar. The Compact Fruit Tree, 35 (1): 1920.

Goffreda, J.C., Voordeckers, A., Mehlenbacker, S.A., 1995. "NJ55" Apple. HortScience, 32 (2): 387-388.

Granger, R.L., Khanizadeh, S., Groleau, Y., Fortin, C.N., 1997. "Primevere" Apple. HortScience, 32 (2): 331-332.

Güleryüz, M., 1977. Erzincan'da Yerleştirilen Bazı Önemli Elma ve Armut Çeşitlerinin Pomolojileri ve Döllenme Biyolojileri Üzerine Araştırmalar. Atatürk Üniversitesi Yayınevi, No: 229, 181s., Erzurum.

Hernandez, D.B., Ciordia-Ara, M., Coque-Fuertes, M., Pereira-Lorenzo, S., 2003. Performance 
of Six Asturian Apple (MalusxDomestica) Cultivars Growing on Two Rootstocks for Cider Production. Journal of the American Pomological Society, 57 (3): 121-127.

Janick, J., Cummis, J.N., Brown, S.K., Hemmat, M., 1996. Apples. Fruit Breeding 1, Tree and Tropical Fruits, John Wiley and Sons, Inc. 77p., NewYork.

Janick, J., 2001. "GoldRush" Apple. Journal American Pomological Society, 55 (4): 194196.

Karadeniz, T., Gökalp, G., 1996. Ulus ve Maden ilçelerinde yetiştirilen mahalli elma çeşit ve tipleri üzerinde pomolojik ve morfolojik çalışmalar. YYÜ, Zir. Fak. Dergisi, 6 (2): 115125.

Karlıdağ, H., Eşitken, A., 2006. Yukarı Çoruh Vadisinde Yetişen Elma ve Armut Çeşitlerinin Bazı Pomolojik Özelliklerinin Belirlenmesi. Y.Y.Ü.Z.F. Dergisi, 16 (2): 9396.

Kaya, T., Balta, F., 2014. Van Yöresi Elma Seleksiyonları-2: Periyodisiteye Kismi Eğilim Gösteren Genotipler. Akademik Zir. Dergisi, 2 (2): 91-98.

Kırkaya, H., Balta, M., Kaya, T., 2014. Perşembe (Ordu/Türkiye) Yöresinde Yetiştirilen Elma Genotiplerinin Pomolojik, Morfolojik ve Fenolojik Özellikleri. Journal of the Institute of Science and Technology, 4 (3): 15-20.

Lei, Z.Y., Xu, Q.H., Ming, Z.X., 1996. The New Early Apple Selection 135-1. South China Fruits, 25 (3): 46-47.

Luby, J.J., Bedford, D., 2006. Register of New Fruit and Nut Cultivars. Hortscience, 41 (5): 11011133.

Oğuz, H.i., Aşkın, M.A., 1993. Erciş'te Yetişen Mahalli Elma Çeşitlerinin Morfolojik ve Pomolojik Özellikleri Üzerine Araştırmalar. YYÜ. Zir. Fak. Dergisi, 3 (2): 281-298.

Osmanoğlu, A., 2008. Posof (Ardahan) Yöresi Elma Genetik Kaynaklarının Fenolojik, Morfolojik, Pomolojik ve Moleküler Tanımlanması. (doktora tezi, basılmamış). YYÜ Fen Bil. Enst., Van.

Osmanoğlu A., 2019. M9 Anacı Üzerine Aşılı Standart Elma Çeşitlerinin Bazı Fiziksel Gelişim Durumlarının incelenmesi. II. Uluslararası Battal Gazi MultiDisipliner Çalışmalar Kongresi, 15-17 Mart 2019, s:1038-1047, Malatya.

Osmanoğlu, A., Balta, F., 2021. Posof Yöresi Elma Popülasyonunda Periyodisite Göstermeyen Tiplerin Belirlenmesi. Türk Tarım ve Doğa Bilimleri Dergisi, 8 (2):388-395.

Özbek S, 1977. Genel Meyvecilik. Çukurova Üniversitesi Yayınları No: 111, Adana. 386.
Özbek S, 1978. Özel Meyvecilik. Ç.Ü.Z.F. Yayınları, No: 128 , Adana. 486s.

Özbek S, 1993. Genel Meyvecilik. Ç.Ü.Z.F. Yayınları, No: 31, Adana. 386s.

Pırlak, L., Güleryüz, M., Aslantaş, R., Eşitken, A., 1997. Erzurum İlinin Tortum ve Uzundere İlçelerinde Yetişen Yazlık Elma Tiplerinin Seleksiyon Yoluyla Islahı Üzerinde Bir Araştırma. Yumuşak Çekirdekli Meyveler Sempozyumu. 2-5 Eylül 1997, s: 21-28, Yalova.

Serdar, Ü., Ersoy, B., Öztürk, A., Demirsoy, H., 2007. Saklı Cennet Camili'de Yetiştirilen Yerel Elma Çeşitleri. V.Ulusal Bahçe Bitk. Kong., 4-7 Eylül 2007, s: 575-579, Erzurum.

Şen, S. M., Bostan, S.Z., Cangi, R., Kazankaya, A., Oğuz, H.I.., 1992. Ahlat ve Çevresinde Yetiştirilen Mahalli Elma Çeşitlerinin Morfolojik ve Pomolojik Özellikleri. YYÜ, Ziraat Fak. Dergisi, 2 (2): 53-65.

Şenyurt, M., Kalkışım, Ö., Karadeniz, T., 2016. Gümüşhane Yöresinde Yetişen Bazı Standart ve Mahalli (malus communis L.) Çeşitleri. Bahçe, Atatürk Bahçe Kültürleri Merkez Araştırma Enst. Dergisi, 45 (1): 579-582, Yalova.

Tolmacheva, A.S., 1991. Lada Winter Apple Veriety. Horticutural Abstracts, 61 (6): 52. 